\title{
Catherine Marin. «Les relations de voyage d'Occidentaux (missionnaires, marchands et diplomates) en Perse au XVIIe siècle »
}

\section{Denise Aigle}

\author{
(2) OpenEdition \\ Journals \\ Édition électronique \\ URL : https://journals.openedition.org/abstractairanica/52648 \\ DOI : 10.4000/abstractairanica.52648 \\ ISSN : 1961-960X \\ Éditeur : \\ CNRS (UMR 7528 Mondes iraniens et indiens), Éditions de l'IFRI
}

Référence électronique

Denise Aigle, "Catherine Marin. "Les relations de voyage d'Occidentaux (missionnaires, marchands et diplomates) en Perse au XVIle siècle » », Abstracta Iranica [En ligne], Volume 42-43 | 2021, document 1 , mis en ligne le 15 avril 2021, consulté le 24 décembre 2022. URL : http://journals.openedition.org/ abstractairanica/52648 ; DOI : https://doi.org/10.4000/abstractairanica.52648

Ce document a été généré automatiquement le 24 décembre 2022.

Tous droits réservés 


\title{
Catherine Marin. « Les relations de voyage d'Occidentaux (missionnaires, marchands et diplomates) en Perse au XVIIe siècle »
}

\author{
Denise Aigle
}

\section{RÉFÉRENCE}

Catherine Marin. « Les relations de voyage d'Occidentaux (missionnaires, marchands et diplomates) en Perse au XVIIe siècle », Mélanges de l'Institut dominicain d'études orientales, vol. 35, 2020 (Dossier - Les interactions entre (šîites imāmites et chrétiens), p. 101-116.

1 Pourquoi la Perse a-t-elle suscité tant d'intérêt en Occident au XVII ${ }^{e}$ s., et pourquoi tant de voyageurs ont-ils rejoint cette contrée lointaine, rédigeant nombre de rapports, récits de voyage intéressant autant les gouvernants européens, les autorités des Églises que le grand public, s'interroge C. Marin au début de son article. C'est à ces questions qu'elle va tenter de répondre en s'appuyant sur trois relations de voyages : celle d'un marchand, François de la Boullaye Le Gouz (1623-1668), le journal de voyage de Jean Chardin (1643-1713) et les écrits du frère Raphaël du Mans (1613-1696). La raison principale qui justifie l'arrivée des Européens en Perse est sa situation de zone carrefour qui doit se défendre contre les tentatives de ses voisins, certains avides de conquêtes territoriales, obligeant le Shāh à organiser une présence militaire aux frontières et à sécuriser les trois grandes routes qui mènent à la capitale, Ispahan. La ville était le centre des échanges commerciaux, intellectuels, et religieux. Les marchands (anglais, hollandais, russes, polonais et français) y installent des maisons- 
comptoirs qui servent de lieu de repos pour les voyageurs en partance vers l'ExtrêmeOrient, tout en envisageant de prospecter les richesses du pays.

2 Au milieu du XVII ${ }^{e}$ s. de nombreux ordres religieux s'installent également en Perse. Dans une lettre adressée en 1670 à Colbert, le frère Raphaël du Mans en donne la liste. Les augustins, en premier lieu, ont envoyé deux premières ambassades en 1579 et 1582, suivies d'une autre délégation en provenance de Goa en 1602. Les carmes s'implantent à Ispahan en 1608 et fondent ensuite d'autres lieux de mission à Ormuz, Chiraz, Bandar Abbas, Hamadan et Jolfa. Puis, les capucins français fondent une première mission en 1628 jusqu'à l'arrivée de Raphaël du Mans qui, à partir de 1644, développe l'étude des langues et des sciences à Ispahan. Enfin, les jésuites arrivent en 1645, ils ouvrent une maison dans le quartier des Arméniens de Jolfa, en périphérie d'Ispahan, ensuite une deuxième mission arrive en 1652 qui s'établit cette fois dans la capitale.

Tout au long du XVII s., le gouvernement politique de la Perse accueille avec une certaine bienveillance ces Européens, diplomates, voyageurs, marchands, missionnaires et autorise assez facilement leur installation dans les grandes villes de Perse. Pour le Shah, cette présence occidentale sert sa politique de recherche d'alliances contre l'Empire ottoman, et ouvre aussi de sérieux débouchés commerciaux à tous les biens fabriqués en Perse, en particulier la soie et les étoffes précieuses. La Perse safavide est devenue au XVII $\mathrm{s}$. un empire centralisé qui apparait comme un allié de poids dans la région. Shāh 'Abbās I ${ }^{\text {er }}$ s'est couvert de gloire non seulement grâce à de grandes victoires militaires contre les Ottomans dont l'écho est parvenu jusqu'aux cours européennes, mais aussi grâce à ses succès militaires contre les Portugais qui furent chassés en 1602 de l'île de Bahrayn, puis en 1622 de l'île d'Ormuz. L'ensemble de ce background politique explique l'arrivée de ces ambassadeurs, missionnaires et voyageurs européens en Perse safavide.

\section{AUTEURS}

\section{DENISE AIGLE}

UMR 8167 - Orient et Méditerranée 